\title{
The Development of Teacher Competencies in the Preparation of a Lecture and Seminar Course in Geography
}

\author{
Galina S. Samigullina * (a), Kulash N. Mamirova (b), Renat I. Gaisin (c), \\ (a), (c) Kazan Federal University, 420008, Kazan (Russia), 18 Kremlyovskaya street, \\ galinaterra@yandex.ru
}

\begin{abstract}
In world education, there is a tendency towards an activity approach. Attention is paid to active forms of learning. The problem of the role and purpose of the modern lecture, its specificity, and the competencies of the modern teacher in the context of the implementation of the activity approach is being actualized.

The main theoretical and methodological questions on the lecture-seminar system were developed in the scientific literature. Considering the activity paradigm of education, future teachers do not have a good enough way of life, including the manifestation of various deviations. The latter has not yet been sufficiently studied in modern research.

The purpose of this study is the formation of constructive and organizational-activity competencies of the future teacher in the design of lecture and seminar classes in geography. The main research methods are systemic and situational analysis, graphoanalytical method of mental and temporary mismatch of seminar lessons. The experiment was attended by the second- year masters of Kazan Federal University.

The use of the graphoanalytical method of testing masters allowed us to bring future teachers to an operational and productive understanding of the lessons of lecture and seminar lessons on the example of geography.
\end{abstract}

Keywords: lecture class, learning density of a class, types of memory, active attention, tempo-rhythmical pattern of a class, rhetoric, reversion.

(C) 2020 Galina S. Samigullina, Kulash N. Mamirova, Renat I. Gaisin

This is an open access article distributed under the terms of the Creative Commons Attribution License (CC BY 4.0), which permits unrestricted use, distribution, and reproduction in any medium, provided the original author and source are credited.

Published by Kazan federal university and peer-reviewed under responsibility of IFTE-2020 (VI International Forum on Teacher Education)

* Corresponding author. E-mail: galinaterra@yandex.ru 


\section{Introduction}

At present, in many countries, even in economically developed and stable states, there is an ongoing transformation of family values and traditional foundations. Rather serious changes are taking place in the family and marriage institution. The crisis of family is particularly evidenced by the decrease in the prestige of the family, degradation of the family lifestyle, lack of need to have children, an increase in domestic violence and number of divorces, as well as in growing share of alternative marriages and family relations.

The relevance of the study is stemming from the increasing importance of the family institution for the stability of society and the state. An orderly family can be created only assuming a certain readiness of young people for family life. Pursuant thereto, there is undoubtedly a growing role of preparation of the younger generation for future family life, and, obviously, it is necessary to develop pedagogical foundations for the implementation of this process.

According to the Russian scientists, preparation for future family life is one of the main tasks young people address in the period of their adolescence and youth (Isaev \& Kagan, 1986; Dorno, 1990). This age range is defined as a crucial period in the formation of gender identity, sex-role stereotypes that underlie family interaction.

It is important to note that individualized ideas of adolescents at risk about the institution of the family, most often, are distorted or formed inadequately, as the basis of the deviant behavior of adolescents rooted in the improper upbringing in the family.

Consequently, the problem of developing readiness of deviant behavior-prone adolescents for family life, besides being relevant, is also of great social significance.

\section{Purpose and objectives of the study}

Purpose of the study is to empirically test the effectiveness of the developed pedagogical conditions for development of readiness of troubled adolescents for family life.

\section{Literature review}

The technique of giving lectures as an active teaching method is described in the works of Podlasiy (1996) and Slastyonin (2011). 
So, what is the real role and purpose of a modern lecture? What are the specifics of it? What competencies should a modern teacher possess?

The competency, according to UNESCO definitions (to know how to study, act, live together, exist), is essentially is a complex of professional knowledge and professionally important personal qualities that provide effectiveness of the professional work.

The teacher's competencies are aimed at the preparation of a whole complex of the students' skill and knowledge (Paul \& Elder, 2014).

The competencies are personal qualities and actions that provide the effectiveness of work, which can be used in various forms and types of activities, can be developed by training and formed in a reflexive way (Ferrandez-Berrueco \& Sanchez-Tarazaga, 2014).

Among the teacher's competencies is the ability to use new technologies in educational process, understand and acquire professional skills (Suciu \& Mâţă, 2010).

The importance of lecture classes:

a) They develop the ability to listen and acquire information, follow the track of the speaker's thoughts and take notes briefly. The lecturer is the holder of "vivid" knowledge who introduces the listener to the secrets of the scientific thinking. It is worth mentioning the words of Comenius here: "relying on the memory alone is the same as writing on the surface of the water, as our memory is flimsy and captures so many things that quit it in no time if not protected by the enclosure of writing". (Grontsova, 2015)

b) The lecturer's speech serves as an example of logical and coherent presentation;

c) High informative capacity and multidimensional approach, a possibility to convey quite a large volume of educational material in a short period of time.

Informational function of a lecture was considered its main function in the past. Today activity-based functions: motivational, practice-oriented, value-based, methodological, evaluation and developmental ones are also included with it. 
The motivational function is crucial at the stage of preparation, as the success of the lecture depends on the ability of the teacher to arouse an interest for the studied material, awake cognitive needs and persuade the students in theoretical and practical value of the educational material.

The practice-oriented function marks moving from factual (declarative) through operational (procedural) to productive (heuristic, creative) approach to lectures.

The operational (procedural) approach implies referring to textual, tabular, cartographic and statistic sources, to reference materials etc.

Heuristic or creative level implies transformation of the acquired material, development and manifestation of intellectual abilities through challenges, tasks etc.

The main point of the value-based function involves understanding and accepting of the studied material and development of abilities.

The methodological function as the activity-based approach sees it, becomes even more important as we need to develop an integrative scientific worldview and achieve metadisciplinary educational results: the use of scientific methods and principles of thinking.

The main goal of the evaluation and developmental function is the initiation, support and inspiration of the student's personal development according to the natural reflective self-development technique. This approach helps to nurture thinking skills and teaches the self-evaluation techniques.

The plan of a lecture defines tasks and problems for the students. It should contain a few clear and concise items that convey the main point of the lecture.

The material is selected according to the objective and educational tasks of the lecture. It should demonstrate high scientific quality and provide students with an understanding of the relationships between social and environmental processes. The lecture should implement problematic approach, include carefully selected material and avoid overload with less important details, minor facts and examples. Retelling of the textbook content is also inadvisable.

The main instructional techniques that encourage effective listening during the lecture are:

- Constant guidance through the lecture (distinctive conceptual blocks, setting up a problem or a task before each of them, comprehension check, summarizing conclusion); 
- Engaging the students in making lecture plans, extracting bullet points; regular statement accuracy control;

- Setting up tasks and challenges to encourage students to analyze, compare, make assumptions, reject, reason, make conclusions and develop their scientific thinking;

- Elements of dialogue;

- The use of verbal and visual means, technical teaching aids.

Rhetorical principles:

- The use of specific words instead of general ones, e.g. "a table" and not "a piece of furniture", so that the listener could "touch" the object;

- Lexically and grammatically correct speech;

- Wide-ranging vocabulary;

- Emphatic speech;

- Capture the listener's attention;

- Keep it moving: the listener should always know where he/she is;

- During the lecture use the plan previously written on the white board;

- Redundancy and tautology elimination: "a variety of different items", "future plans", "I went to see him personally."

- Avoidance of synonym combinations like in "memorable souvenirs".

A reasonable dose of humor can liven up the lecture. The British kind of humor will be just right - it will lighten the atmosphere in the classroom without loss of productivity. The teacher should remember that by the middle of the lecture for an unprepared audience the speech rate of a lecturer exceeds the writing speed of students therefore leaving them behind. This is why the method of reversion is used, including repetition of modified phrases, explanations and logical digressions to previously mentioned concepts (Dyusamaliyeva, 2007). 
A stage-by-stage approach is also essential. The first stage of a lecture is making eye contact with the audience. The second stage is the "intensification" including the articulation of the goal of the class. The third stage is a pause or "plateau" used to transfer the information from short-term memory into long-term memory. The point is that usually only about last 5-6 pieces of information are transferred into long-term memory.

Long-term memory is divided into:

- Episodic memory that stores specific events. It is susceptible to interference, i.e. it changes as the new information arrives depending on its volume, difficulty and characteristics: whether it is interesting or not, common or unusual.

- Semantic (or cluster) memory that stores all similar elements belonging to the same category;

- Group memory that reproduces elements from categories with similar attributes;

- Network memory that reproduces information connected with associations and relations; the model of comparative semantic features: essential and determinant, or immanent and characteristic ones.

The reproductive function of short-term memory is insufficient. Conscious repetition is required to save all the information. The main techniques of conscious memorization are well-known: extracting the main points, comparison and contrast, the use of specific examples, active and varied spaced repetition, the combination of visual, verbal and logical representation of material, data classification.

Practical rules:

- Dynamic presentation and active perception of information;

- emotionally expressive information;

- serial position effect;

- smart lecture conclusion;

- individual memory characteristics;

- "hint", forming associations and relationship with previously studied material;

- Focus on long-term memorization. 


\section{Methodology}

According to Ushinsky, the passive attention is based on the emotion-charged material. At the same time according to the law of the unity and struggle of opposites, emotions can both reinforce the memorization process and distort the received information (1968).

The isolated fragments of material are memorized better than the information taken out of the context, but associative links are more important than logical ones. Repetition is more effective when it is spread out over a period of time. Repetition directly depends on the focus, and it makes no sense without focused attention. Uncommon, unusual, harsh, personally interesting ideas are memorized more easily.

According to the law of cognitive psychology, reproduction capacity is 3-4 times less than storage capacity.

A key factor for a good memory is the ability to systematically arrange the material to be memorized in your brain.

Cognitive dissonance becomes the foundation of the development, activity and self-motivation, as it stimulates a person to eliminate the inconsistency of their knowledge. Cognitive activity is stimulated under conditions which can be enhanced by a certain learning technology. This technique detects changes in individual mental thesauruses that happen when the problems are solved not by means of reproduction of previously acquired information (recalling), but by actively handling and transforming the data as long as the prolaticity level correlates with the student's thesaurus.

The last stage is the lecture as it is. During the lecture the teacher should keep in mind the laws of cognitive psychology that investigates perception, storage, processing, reproduction and use of the received information.

Stanislavski (2018) names attention and tempo-rhythm among 24 elements of acting skills.

Emile Jaques-Dalcroze, who was an innovative educator, composer, organ and piano player, the inventor of musical and rhythmical education system, also investigated the idea of tempo-rhythm.

Emile Jaques-Dalcroze and Stanislavski attached great importance to teaching and learning in an emotionally comfortable and joyful climate based on deep knowledge of psychological and physiological specifics. 
Tempo-rhythm (the $15^{\text {th }}$ place) means physical and mental actions performed at a certain pace during a certain time (Butenko, 2005).

Stanislavski suggested the following tempo-rhythmical pattern during a class: $2-3-1-2-4$, where 1 is low speed, 2 is a little slower than 3, 3 is moderate speed, and 4 is high speed.

Stanislavski connected this tempo-rhythmical pattern of a class with attention that takes the $1^{\text {st }}$ place among 24 elements of acting skills and works as a conduit of feelings. "I see what is given and treat it with a desired attitude" is a rule of scenic attention according to Stanislavski (2018).

Psychological researches determined individual and age-specific peculiarities of the students' attention. According to various researches the lecture duration in senior classes should not exceed 25-30 minutes.

Koptseva, the principal of a senior high school in Ulyanovsk revealed in her studies that the period of active (sustained) attention of 7-year-old students is 7-12 minutes, of 10-year-old students is 16-20 minutes, of 11-year-old students is up to 25 minutes and 27 minutes for senior students (2003).

The main problem of geography as a school subject is a multi-layered gradation of required knowledge, skills and abilities contrasted with reducing study time. Keeping this in mind, the teacher should remember about the learning density of a class:

$\hat{Y}=\mathrm{v}: \mathrm{t}$

where $\mathrm{v}$ is the volume of the studied material,

$\mathrm{t}$ is sustained attention period (Dyusamaliyeva, 2007).

As it turned out, the volume of the studied material is quite large and includes factual geographic information, notions, concepts, laws, theories, nomenclature, whereas sustained attention period is 27 minutes on average. This is the reason why the knowledge of psychology, age-appropriate pedagogy, the content and teaching methodology of the subject is crucial for a teacher.

The sustained attention period begins in the interval of 15-20 minutes, 30-35 minutes from the beginning of the class, when the visual and auditory information changes. Protective inhibition takes place between the 20 and 25 minutes of the class.

In spite of the fact that the visual capacity of a human eye is millions of bits and the auditory capacity of a human ear is tens of thousands of bits, the perceptual speed of a human brain is a fraction of its visual and 
auditory bandwidth. The speech rate of about 2,5 words a second is required for appropriate speech perception. This means that selection and filtration of incoming information is essential. Short-term memory that operates for more than 12 seconds provides interpretation of observed events rather than mere representation of them.

A lecture at school differs from that at university as the former employs at least three methods. Multimedia content designed for simultaneous visual and auditory perception of the learning material is the best choice for geography classes. Educational slide films are effective with extra technical devices. Educational TV programs are more advanced instructional means, but they are almost never used. Educational short films require temporary blackout which is ineffective, as it takes up to 30 minutes for visual adaptation and 15 seconds for auditory adaptation. Educational videos are inferior as compared to mobile computers and multimedia projectors, as they require conversion into analogue or digital form.

$90 \%$ of information is received through the visual channel and $9 \%$ of it received through the auditory one. $25 \%$ of the information is memorized through the visual channel and $15 \%$ of it is memorized through the auditory one.

As a result, $65 \%$ of information is memorized when both channels - visual and auditory - are used, though the result is influenced by many other factors: knowledge, motivation, the ability of the teacher to arouse interest and emotions in students during the lecture (Azhgibkova, Zverev, \& Lebedeva, 2004).

In a heterogeneous group of students audio-visual messages are more effective than bookwork.

Learning possibilities of audio-visual materials help to activate visual perception channel as the means of argumentation, intensify the students' attention, add some emotions to the lecture, which in the end facilitates solid memorization and reproduction of the material.

When employing visual material, the teacher should clearly determine the period of demonstration, otherwise the attention and memorization focus can shift towards visual means. Visual materials demonstrated during the first 5 minutes help to keep the sustained attention. Suggested demonstration time for an educational film is 10-20 minutes, for a video film is 3-5 minutes. The teacher should also remember about message conveyed through the audio-visual materials, their supportive function as related to theoretical part of the learning material and about other visual aids. The teacher should not overload his/her comments with excessive information nor provoke unnecessary discussion. The emotional background and the content of the visuals should comply with the goals of the lecture. 
The subject of "Economic and social geography of the foreign countries" for the senior classes of high school can be taught in a more efficient way as a course of lectures and seminars.

Features of the seminar classes:

- The seminar preparation takes a significant amount of time (2-3 weeks), with compulsory research through supplemental materials, mainly from the periodical press, and preparation of a reference list of available literature;

- All of the students prepare for the general discussion on the topic given in advance, and some students prepare individual presentations and papers;

- The papers and reports are presented and discussed together during the seminar; general discussion is held based on self-learned and comprehended material;

- The teacher guides the students' activity, gives an opportunity to deliver and listen to different opinions, evaluates the level of activity, overall presentation quality, independence of thought, reasoning quality, consistency of statements, the ability to defend one's point of view;

- The students receive an opportunity to demonstrate their independence and creativity while solving the problems and achieving the tasks.

- The teacher determines the time and place of the selected seminar topic to be included into the schedule (Zhilyayev, 2004).

\section{Results}

The plan of a seminar should include:

- No more than 3-4 specific points to be discussed, otherwise the discussion tends to become shallow and superficial;

- The reference list of required and supplementary literature;

- Special tasks: a brief summary or plan used for preparation of materials for the seminar; 
- Drawing of schemes, maps, charting and tabling; selection of material from regional natural history sources and periodical press;

- Making of characteristics, assessment of conditions (environmental, socio-economic, geopolitical etc.), estimation of perspectivity, conceptual foresight;

The testing of second year master students using graphical analytic method demonstrates the mismatch of mental and temporal disagreement of seminar classes despite the students' clear view of special aspects of seminar classes (Table 1).

Table 1. Mismatch of mental and temporal disagreement of seminar classes

\begin{tabular}{|c|c|c|c|c|c|c|c|c|c|}
\hline \multirow{2}{*}{ № } & \multirow{2}{*}{$\begin{array}{l}\text { The master } \\
\text { student's } \\
\text { name }\end{array}$} & \multicolumn{8}{|c|}{ The seminar weeks (using 1,2 and 4 school terms as an example) } \\
\hline & & 1. & 2. & 3. & 4. & 5. & 6. & 7. & 8. \\
\hline 1. & Alexander & & & + & & & & & \\
\hline 2. & Alina & & & & & & & + & \\
\hline 3. & Kseniya & & & & & + & & & \\
\hline 4. & Nastya & & & & & & + & & \\
\hline 5. & Ram & & & & & & & + & \\
\hline 6. & Rinat Yu & & & & & + & & & \\
\hline 7. & Yulia & & & & & & + & & \\
\hline 8. & Insaf & & + & & & & & & \\
\hline 9. & Alexey & & + & & & & & & \\
\hline 10. & Ilyas & & + & & & & & & \\
\hline
\end{tabular}

The graphical analytic method clearly demonstrates the mismatch of mental and temporal disagreement of seminar classes using the shortest 1,2 and 4 school terms as an example (Figure 1). 


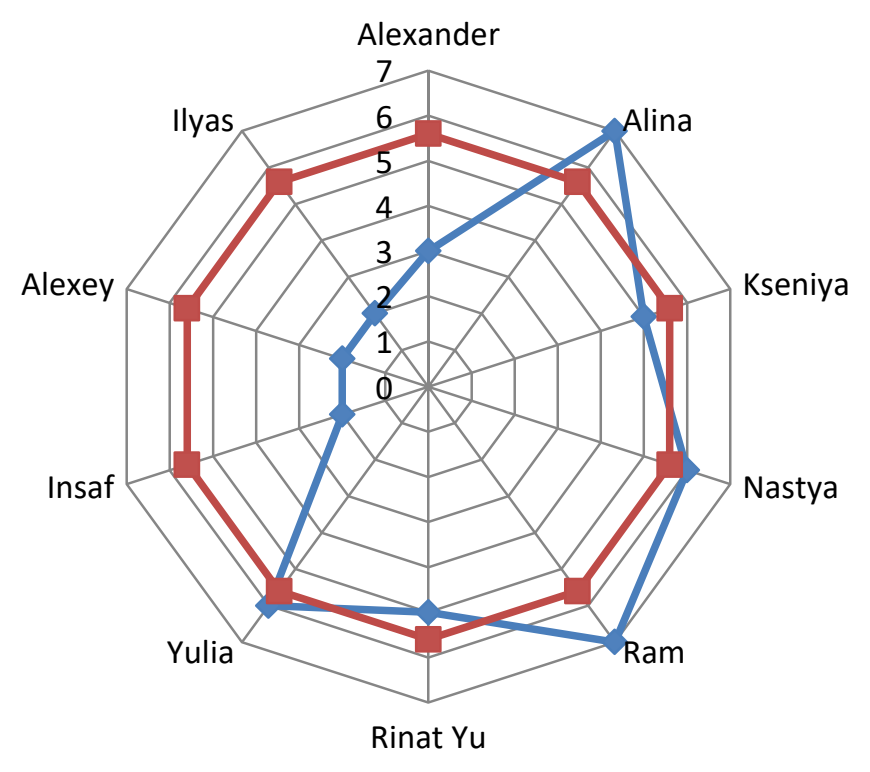

$\sim$ Row 1 mental view of the master students about time of seminar delivery

Row 2 Recommended time for delivering a seminar

Figure.1 Mismatch of mental and temporal disagreement of seminar classes.

\section{Discussions}

At the ascertaining stage of the experiment, the following levels of dissonance of mental and temporal mismatch were revealed during the design of the lesson-seminars: a). low; b) middle; in). tall.

As a result of using the translation of one form of information to another, significant positive changes were revealed in the operational-productive understanding and practical use of lecture and seminar lessons.

\section{Conclusion}

Lecture classes are usually perceived as purely monological form of educational process, but enriched with the knowledge of cognitive psychology, specific aspects of the studied subject and multimedia materials, they will lead to operationally productive comprehension of the lecture classes. Binary organization of lecture and seminar course provides quality acquisition of information in the context of reduced hours spent on the subject in school curriculum preserving the scope of knowledge.

\section{References}

Azhgibkova, T. N., Zverev V. V., \& Lebedeva M. L. (2004). The technology of audio-visual means implementation in university education, Innovatsii v obrazovanii [Innovation in Education], 2, 111-123. 
Butenko, E. (2005). Stage transformation: theory and practice. Moscow: Prikosnovenie.

Dorno, I. V. (1990). Modern marriage: problems and harmony. Moscow: Pedagogica.

Dyusamaliyeva, G. S. (Samigullina G.S.). (2007). The lecture course for geography teachers. Kazan: Kazan Federal University.

Grontsova, I. (2015). The socio-pedagogical thinking of J. A. Comenius. Bulletin of South Ural State University, 7(3), 16-21.

Ferrandez-Berrueco, R., \& Sanchez-Tarazaga, L. (2014). Teaching competences in Secondary Education. Journal of Educational Research, Assessment and Evaluation,20(1), 1-20.

Isaev, D. N., \& Kagan, V. E. (1986). Sex education of children. Saint Petersburg: Lenizdat.

Main elements of Stanislavski's system [online article]. (2018). Retrieved from https://studopedia.info/88138.html

Koptseva, L. N. (2003). 30-minute class preparation technology. Metodist, 5,43-46.

Paul, R., \& Elder, L. (2014). Critical thinking. New Jersey: Prentice-Hall.

Podlasiy, I. P. (1996). Pedagogika. Pedagogics. New Course. Book 1. Fundamentals. Educational process. Moscow: Vlados.

Slastyonin, V. A. (2011). Pedagogy. Saint Petersburg: Akademia.

Suciu, A. I., \& Mâţă, L. (2010). Conceptual delimitations regarding pedagogical competenc(i)e(s). Journal Plus Education, 6(2), 189-200.

Ushinsky, K. D., (1968). Selected pedagogical works. Moscow: Prosveshenie.

Zhilyayev, A. A. (2004). Psychological aspects of preparation and giving seminars and practical classes, Innovatsii v obrazovanii, [Innovation in Education], 3, 139-152. 